\title{
ANALISIS TINGKAT CEMARAN LOGAM TEMBAGA DAN TINGKAT PENDAPATAN USAHATANI SAYURAN DI KEBUN KARTAMA DAN KEBUN KOMPPOS - EM KOTA PEKANBARU
}

\author{
Shally Yanova, Zulkarnaini, Sofia Anita
}

\begin{abstract}
Alumni Pascasarjana Ilmu Lingkungan Program Pascasarjana Universitas Riau, Dosen Pascasarjana Ilmu Lingkungan Program Pascasarjana Universitas Riau, Pekanbaru, J1. Pattimura No.09.Gobah, 28131. Telp 0761-23742. e-mail: shallyyanova@gmail.com
\end{abstract}

\section{ABSTRACT}

The study was done in August to September 2015 and located in the Kartama Garden (PSN) on Kartama street Marpoyan Damai district area and KOMPPOS - EM garden (PSO) at the University of Riau, Pekanbaru. The purpose of this research is determining metal Cu (copper) in vegetable (mustard, convolvulus and lettuce) and soil, determining the rate of pollution metal $\mathrm{Cu}$, analyzing the use of fertilizer and pesticide synthetic levels of metal $\mathrm{Cu}$ in a sample and analyzing the impact of agricultural income activity for farmers. Based on the research, levels of metal $\mathrm{Cu}$ in vegetables and soil PSN had passed of quality standard Director General POM RI namely 5,0 mg/kg and categorized polluted metal Cu. While sample vegetable KOMPPOS - EM garden (PSO) is still under environmental quality category and including contaminated. Using fertilizer and pesticide synthetic and continuing to exceed doses constantly affects levels of metal $\mathrm{Cu}$ in a sample of vegetables and soil significantly. Economically, PSN and PSO farming is agricultural activity that can give advantages for farmers.

Keywords: Pollution, Metal Cu (copper), Vegetables, Soil.

\section{PENDAHULUAN}

Indonesia merupakan salah satu negara berkembang yang mayoritas penduduknya memiliki sumber mata pencaharian di sektor pertanian. Sebagian besar lahan di Indonesia diperuntukkan sebagai lahan pertanian dan hampir $50 \%$ dari total angkatan kerja masih menggantungkan nasibnya bekerja di sektor pertanian (Husodo, 2004). Salah satu komoditi pertanian yang cukup berpotensi di Indonesia adalah sayuran.

Setyawan (2009) menyatakan bahwa tanaman sayuran merupakan produk pertanian yang dikonsumsi setiap saat, sehingga mempunyai arti nilai komersial yang cukup tinggi. Adapun tanaman sayuran yang cukup potensial diusahakan dan memberikan keuntungan yang cukup tinggi misalnya sawi hijau (caisim), sawi sendok (pakcoy), mentimun, kacang panjang, bayam, kangkung, dan sayuran semusim lainnya.

Bahan pangan seharusnya memenuhi kriteria ASUH (Aman, Sehat, Utuh dan Halal). Salah satu parameter tersebut, yaitu Aman, termasuk dalam masalah mutu. Mutu dan keamanan pangan berpengaruh langsung terhadap kesehatan masyarakat dan perkembangan sosial. Makanan yang bermutu baik dan aman diperlukan untuk meningkatkan kesehatan manusia, kesejahteraan individu dan kemakmuran masyarakat (Widaningrum et. al., 2007).

Namun, keamanan bahan pangan seperti sayuran dapat terancam akibat penggunaan pupuk dan pestisida sintetik pada aktivitas pertanian. Zat pencemar yang berasal dari pupuk dan pestisida biasanya berupa logam berat maupun senyawa yang merupakan residu dari pupuk. Terjadinya akumulasi logam berat seperti logam $\mathrm{Cu}$ (tembaga) dalam tanah dan tanaman merupakan salah satu dampak negatif dari penggunaan pupuk dan pestisida sintetik yang mengandung logam berat tersebut secara berlebihan untuk aktivitas pertanian.

Salah satu lokasi pertanian sayuran terbesar di Kota Pekanbaru berada di Jalan Kartama Kec. Marpoyan Damai. Para petani setempat masih menggunakan pestisida sintetik dan tidak sesuai dengan aturan dosis yang ada. Selain itu, para petani selalu menggunakan pupuk kandang 
kotoran ayam, pupuk kimia pada pertanian sayuran yang dominan ditanam yaitu bayam, kangkung darat, sawi dan selada (Simanjuntak, 2014). Kegiatan pertanian yang menggunakan pupuk dan pestisida sintetik secara terus menerus dapat menyebabkan pencemaran lingkungan, baik pada komponen abiotik (tanah) maupun pada komponen biotik (tanaman).

Penggunaan pupuk kandang, pupuk sintetik dan pestisida sintetik (insektisida dan fungisida) merupakan sumber utama kontribusi logam $\mathrm{Cu}$ (tembaga) pada tanah dan tanaman. Cemaran logam $\mathrm{Cu}$ (tembaga) pada bahan pangan dapat terjadi karena penggunaan pupuk dan pestisida secara berlebihan. Meskipun demikian, pengaruh proses pengolahan akan dapat mempengaruhi status keberadaan tembaga tersebut dalam bahan pangan (Charlena, 2004). Dirjen Pengawasan Obat dan Makanan (POM) RI telah menetapkan batas maksimum cemaran logam berat tembaga pada sayuran segar yaitu $5,0 \mathrm{mg} / \mathrm{kg}$.

Apabila logam $\mathrm{Cu}$ (tembaga) telah masuk dalam tubuh manusia, maka dapat menyebabkan keracunan $\mathrm{Cu}$ pada manusia yang dapat mengakibatkan sakit perut, mual, muntah dan diare. Pada beberapa kasus yang parah dapat menyebabkan penyakit hepatic cirrhosis, yaitu kerusakan pada otak serta terjadinya penurunan kerja ginjal dan pengedapan $\mathrm{Cu}$ dalam kornea mata (penyakit Wilson). Gejala ini dapat diketahui dengan terbentuknya rambut yang kaku dan berwarna kemerahan pada penderita (Putra, 2002).

Berdasarkan fakta dan kondisi tersebut, maka perlu dilakukan penelitian untuk mengetahui kandungan logam berat $\mathrm{Cu}$ pada tanah dan sayur - sayuran hasil panen di Kebun Kartama Kec. Marpoyan Damai dan di Kebun KOMPPOS - EM Universitas Riau sebagai pembandingnya.

\section{METODOLOGI PENELITIAN}

Penelitian ini dilaksanakan pada bulan Agustus - September 2015. Tempat pengambilan sampel di Kebun Kartama Kec. Marpoyan Damai (PSN) dan Kebun KOMPPOS - EM Universitas Riau (PSO). Sampel diolah dan didestruksi di Laboratorium Kimia Fisika FMIPA Universitas Riau. Lalu sampel dianalisis secara AAS di Laboratorium UPT Pengujian Material Teknis Dinas PU Bina Marga Provinsi Riau.

Alat - alat yang digunakan adalah: GPS (Global Position System), AAS (Shimadzu AA7000), oven (Galemp Camp), soil tester, termometer tanah, lumpang, hot plate, timbangan analitis, labu takar, desikator, kertas saring Whatman No. 42 dan alat - alat gelas yang biasa digunakan dalam laboratorium. Sedangkan bahan - bahan yang digunakan adalah: sampel tanah dan sayur - sayuran (kangkung darat, selada dan sawi) di Kebun Kartama Kec. Marpoyan Damai dan di Kebun KOMPPOS - EM UR, $\mathrm{HNO}_{3(\mathrm{p})} 65 \%$ p.a., $\mathrm{HCl}_{(\mathrm{p})}$ $37 \%$ p.a., aqua DM dan Larutan Standar $\mathrm{Cu}$ (tembaga).

Penelitian ini menggunakan metode survey, yaitu pengambilan sampel dan melakukan pengujian di laboratorium, wawancara kualitatif dan pengumpulan data sekunder dari Kantor Dinas terkait seperti Dinas Pertanian Kota Pekanbaru dan Badan Pertanahan Nasional Provinsi Riau. Pengambilan sampel untuk observasi dilakukan dengan metode purpossive sampling. Pengukuran sampel menggunakan alat AAS dengan lima (5) kali pengulangan.

- Sampel Tanah

Sampel diambil dari lokasi pertanian, yaitu Kebun Kartama Kec. Marpoyan Damai Kota Pekanbaru dan Kebun KOMPPOS - EM UR masing - masing sebanyak 5 titik dengan memetak/plot $2 \times 2$ meter pada kedalaman 15 $20 \mathrm{~cm}$ sebanyak $\pm 500 \mathrm{~g}$. Lokasi pengambilan sampel diambil pada lahan pertanian sayur organik dan non - organik dengan metode purpossive sampling dan lokasi ditandai menggunakan GPS. Sampel yang diperoleh dimasukkan ke dalam kantong plastik secara terpisah dan dibawa ke laboratorium. Sampel tanah lahan pertanian dibersihkan dari pengotor seperti batu, dicampur dan dikeringkan secara alami. Sampel tanah yang telah siap diuji kemudian didestruksi dengan destruksi basah dan diukur dengan AAS.

- Sampel Sayuran 
Pengambilan sampel sayur dilakukan secara acak dan disesuaikan dengan lokasi pengambilan sampel tanah. Sayuran yang dipilih adalah sayuran yang telah siap panen, masing - masing sebanyak $\pm 1 \mathrm{~kg}$. Sampel dicuci dengan akuades hingga bersih. Setelah itu, tanaman dikeringkan dalam oven pada suhu $105^{\circ} \mathrm{C}$ hingga kering. Sampel yang telah kering kemudian digerus dan dimasukan kedalam plastik agar tidak terkontaminasi serta diberi pelabelan nama dan nomor urut sesuai dengan nomor pengulangan sampel. Sampel tanaman yang telah siap diuji kemudian didestruksi dengan destruksi basah dan diukur dengan AAS.

- Destruksi Basah

Sampel yang telah benar - benar kering diambil $100 \mathrm{~g}$ digerus hingga halus. Dari hasil gerusan, diambil $2 \mathrm{~g}$ sampel dan dimasukkan dalam gelas Beaker $100 \mathrm{~mL}$. Kemudian ditambahkan $20 \mathrm{~mL}$ larutan $\mathrm{HNO}_{3(\mathrm{p})} 65 \%$ p.a. (untuk sampel sayuran), ditambahkan campuran $15 \mathrm{~mL}$ larutan $\mathrm{HNO}_{3(\mathrm{p})} 65 \%$ p.a. dan $5 \mathrm{~mL}$ larutan $\mathrm{HCl}_{(\mathrm{p})} 37 \%$ p.a. (untuk sampel tanah). Campuran dipanaskan di atas hotplate selama 30 menit hingga uap kuning hilang dan terbentuk filtrat jernih. Filtrat dipisahkan dengan menggunakan kertas saring Whatman No. 42. Filtrat diencerkan dengan aqua DM dalam labu takar $50 \mathrm{~mL}$. Sampel diukur dengan AAS pada $\lambda$ $=324,8 \mathrm{~nm}$.

\section{HASIL DAN PEMBAHASAN}

Lokasi pertanian untuk penelitian ini adalah Kebun Kartama Kec. Marpoyan Damai sebagai
Pertanian Sayuran Non-organik (PSN) dan Kebun KOMPPOS-EM Universitas Riau sebagai Pertanian Sayuran Organik (PSO). Survey dilakukan saat musim kemarau yaitu bulan Agustus - September 2015. Pengambilan sampel tanah dan sayuran di Kebun Kartama dilakukan pada tanggal 12 Agustus 2015 didampingi penyuluh petani setempat (Mahoni, S.P), dengan suhu tanah yaitu $29,33^{\circ} \mathrm{C}$. Hal ini dikarenakan pengambilan sampel dilakukan pada sore hari yaitu pukul 17.30 WIB dan sehari sebelum pengambilan sampel di lokasi tersebut pada siang hari terjadi hujan dengan intensitas rendah (Tabel 1).

Sedangkan pengambilan sampel tanah dan sayuran di Kebun KOMPPOS - EM dilakukan pada tanggal 03 September 2015, dengan suhu tanah yaitu sebesar $32,67^{\circ} \mathrm{C}$. Hal ini dikarenakan pengambilan sampel dilakukan pada siang hari yaitu pukul 15.00 WIB. Berdasarkan hasil pengukuran $\mathrm{pH}$, tanah lokasi Kebun Kartama (PSN) termasuk tanah yang sedikit asam dengan pH sebesar 5,87. Sedangkan tanah lokasi Kebun KOMPPOS - EM termasuk tanah netral dengan pH sebesar 7,13 (Tabel 1). Menurut Rumampuk (2008), semakin asam tingkat keasaman tanah maka semakin tinggi kadar logam $\mathrm{Cu}$ (tembaga) dalam tanah dan absorbsi logam $\mathrm{Cu}$ dari tanah ke tanaman pun semakin meningkat. Hal ini dikarenakan tanah yang masam mudah melarutkan logam berat (salah satunya logam $\mathrm{Cu})$.

Tabel 1. Titik Koordinat dan Kondisi Eksisting Lokasi Penelitian

\begin{tabular}{cccc}
\hline Jenis Pertanian & Titik Lokasi & Suhu Tanah $\left({ }^{\circ} \mathbf{C}\right)$ & pH Tanah \\
\hline Pertanian Sayur Non- & $101^{\circ} 43.5^{\prime}$ BT & 29,33 & 5,87 \\
$\begin{array}{c}00^{\circ} 44.5^{\prime} \text { LU } \\
\text { organik }\end{array}$ & $\begin{array}{c}101^{\circ} 37.736^{\prime} \text { BT } \\
00^{\circ} 47.831^{\prime} \text { LU }\end{array}$ & 32,67 & 7,13 \\
\hline
\end{tabular}

Sumber: Data Primer (2015)

Berdasarkan hasil penelitian (Tabel 2), dapat diketahui bahwa kadar $\mathrm{Cu} \pm$ Standar Deviasi (SD) paling tinggi terdapat dalam sampel yang berasal dari Kebun Kartama (PSN) yaitu sebesar 6,270 $\pm 0,0447 \mathrm{mg} / \mathrm{Kg}$ dalam sawi;
$17,525 \pm 0,079 \mathrm{mg} / \mathrm{Kg}$ dalam kangkung; $6,965 \pm 0,0224 \mathrm{mg} / \mathrm{Kg}$ dalam selada dan $40,530 \pm 0,3198 \mathrm{mg} / \mathrm{Kg}$ dalam tanah. Semua sampel sayuran di Kebun Kartama berada diatas ambang batas yang telah ditetapkan Dirjen POM 
RI, yaitu 5,0 mg/Kg (Gambar 1, Gambar 2 dan

Gambar 3). Sedangkan semua sampel sayuran di Kebun KOMPPOS - EM masih berada dibawah ambang batas baku mutu (Gambar 1, Gambar 2 dan Gambar 3).

Berdasarkan indeks $\mathrm{C} / \mathrm{P}$, semua sampel sayuran PSN masuk dalam kategori tercemar logam $\mathrm{Cu}$ (tembaga) dan sampel yang memiliki tingkat cemaran paling tinggi, yaitu pada sampel kangkung PSN yang termasuk kategori cukup tercemar. Hal ini menunjukkan bahwa sayuran PSN mengandung logam $\mathrm{Cu}$ (tembaga) yang dikhawatirkan dapat mengganggu kesehatan masyarakat yang mengkonsumsinya. Sedangkan sampel sayuran PSO masuk dalam kategori terkontaminasi, yang menunjukkan bahwa kadar logam $\mathrm{Cu}$ (tembaga) dalam sayuran tidak memberikan dampak negatif terhadap kesehatan masyarakat yang mengkonsumsinya.

Berdasarkan analisa hasil uji Paired Samples $t$-Test, diketahui bahwa penggunaan pupuk dan pestisida sintetik mempengaruhi kadar logam $\mathrm{Cu}$ (tembaga) yang terdapat dalam sampel tanah dan sayuran secara signifikan.

Tabel 2. Data Hasil Penelitian 1 (Data Primer, 2015)

\begin{tabular}{cccc}
\hline Sampel & $\begin{array}{c}\text { Kadar } \mathbf{C u} \pm \mathbf{S D} \\
(\mathbf{m g} / \mathbf{K g})\end{array}$ & $\mathbf{C} / \mathbf{P}$ & $\begin{array}{c}\text { Hasil Uji Paired Samples t }- \text { Test } \\
(\boldsymbol{\alpha}=\mathbf{0 , 0 5})\end{array}$ \\
\hline Sawi PSN & $6,270 \pm 0,0447$ & 1,2540 & Ada Perbedaan yang Signifikan \\
Sawi PSO & $3,115 \pm 0,1270$ & 0,6230 & \\
Kangkung PSN & $17,525 \pm 0,0790$ & 3,5050 & Ada Perbedaan yang Signifikan \\
Kangkung PSO & $3,185 \pm 0,0675$ & 0,6370 & \\
Selada PSN & $6,965 \pm 0,0224$ & 1,3930 & Ada Perbedaan yang Signifikan \\
Selada PSO & $2,875 \pm 0,0395$ & 0,5750 & \\
Tanah PSN & $40,530 \pm 0,3198$ & 0,4053 & Ada Perbedaan yang Signifikan \\
Tanah PSO & $4,380 \pm 0,1150$ & 0,0438 & \\
\hline
\end{tabular}

Keterangan: $\quad$ PSN = Pertanian Sayur Non-organik (Kebun Kartama)

PSO $=$ Pertanian Sayur Organik (Kebun KOMPPOS - EM)

$\mathrm{C} / \mathrm{P}=$ Indeks Contamination/Pollution

Menurut Fitter dan Hay (1991) dalam Panjaitan (2009) tumbuhan memiliki kemampuan untuk menyerap ion-ion dari lingkungannya ke dalam tubuh melalui membran sel. Dua sifat penyerapan ion oleh tumbuhan adalah sebagai berikut: (1) Faktor konsentrasi, dimana kemampuan tumbuhan dalam menyerap ion sampai tingkat konsentrasi tertentu, bahkan dapat mencapai beberapa tingkat lebih besar dari konsentrasi ion di dalam mediumnya dan (2) Perbedaan kuantitatif akan kebutuhan hara yang berbeda pada tiap jenis tumbuhan.

Faktor - faktor di atas dapat meningkatkan mekanisme penyerapan dan akumulasi $\operatorname{logam} \mathrm{Cu}$ (tembaga) ke dalam tanaman, yang dalam penelitian ini berupa sayuran. Menurut Priyanto dan Prayitno (2007), mekanisme penyerapan dan akumulasi logam berat oleh tanaman dapat dibagi menjadi tiga proses yang sinambung, yaitu sebagai berikut: a. Penyerapan oleh akar.

Logam dibawa ke dalam larutan di sekitar akar (rizosfer) dengan beberapa cara bergantung pada spesies tanaman. Senyawa -senyawa yang larut dalam air biasanya diambil oleh akar bersama air, sedangkan senyawa - senyawa hidrofobik diserap oleh permukaan akar.

b. Translokasi logam dari akar ke bagian tanaman lain.

Setelah logam menembus endodermis akar, logam atau senyawa asing lain mengikuti aliran transpirasi ke bagian atas tanaman melalui jaringan pengangkut (xilem dan floem) ke bagian tanaman lainnya.

c. Lokalisasi logam pada sel dan jaringan.

Hal ini bertujuan untuk menjaga agar logam tidak menghambat metabolisme tanaman. Sebagai upaya untuk mencegah peracunan logam terhadap sel, tanaman mempunyai mekanisme detoksifikasi, misalnya dengan 
menimbun logam di dalam organ tertentu seperti akar.

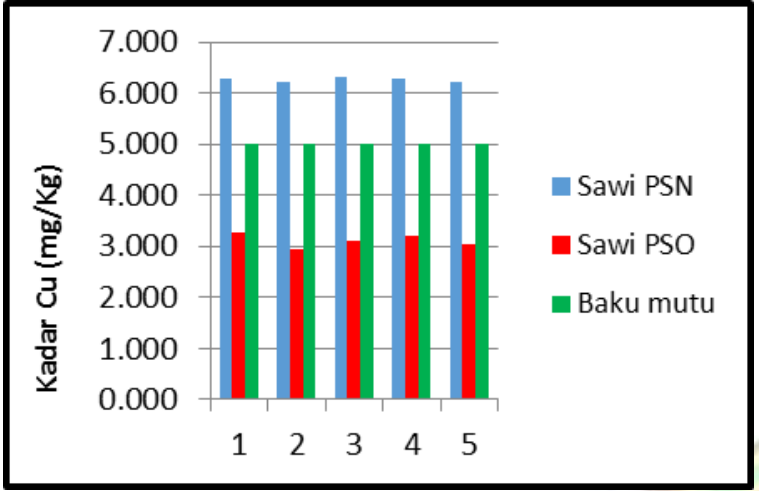

Gambar 1. Kadar Cu (Tembaga) dalam Sayur Sawi

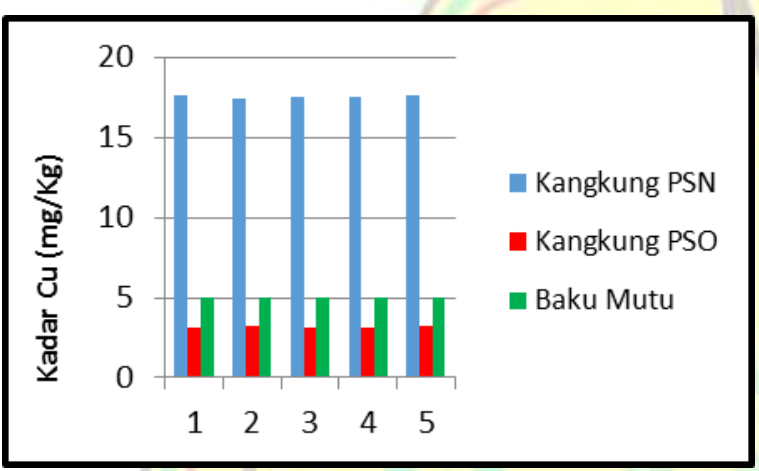

Gambar 2. Kadar $\mathrm{Cu}$ (Tembaga) dalam Sayur Kangkung

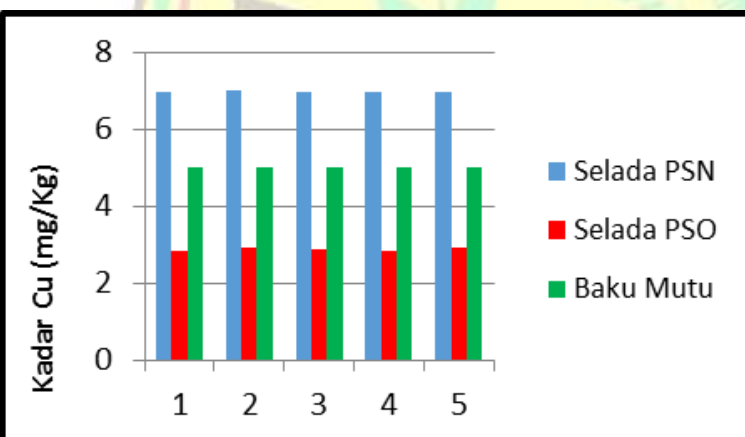

Gambar 3. Kadar Cu (Tembaga) dalam Sayur Selada

Kadar logam $\mathrm{Cu}$ (tembaga) dalam sampel sayur sawi PSN paling rendah dibandingkan dengan sayur kangkung PSN dan selada PSN. Hal ini mungkin dikarenakan oleh perbedaan morfologi tanamannya. Sayur sawi memiliki batang yang keras, daun tebal dan licin sehingga kemungkinan logam $\mathrm{Cu}$ (tembaga) yang terserap oleh akar sawi tidak sampai ditranslokasi ke bagian daunnya. Menurut Darmono (1995), ada beberapa faktor yang mempengaruhi kadar logam berat dalam tanaman antara lain morfologi dan fisiologi tanaman, lamanya paparan logam berat pada tanaman, kadar logam berat dalam tanah, umur tanaman dan faktor yang mempengaruhi areal seperti banyaknya tanaman penutup serta jenis tanaman di sekeliling tanaman tersebut.

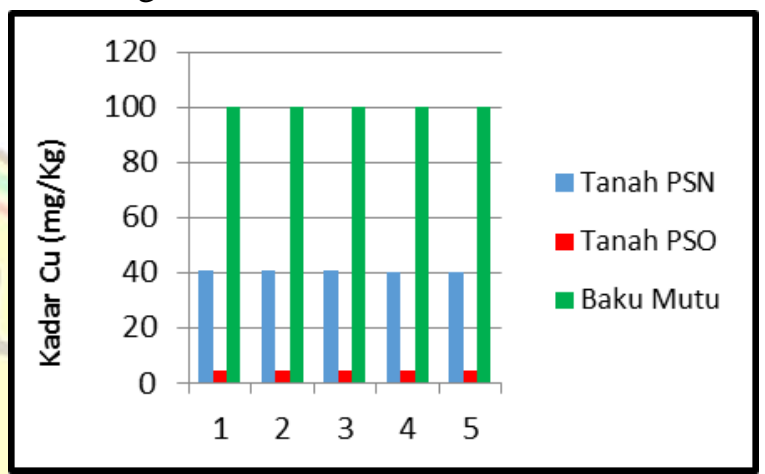

Gambar 4. Kadar Cu (Tembaga) dalam Tanah

Tingginya kadar logam $\mathrm{Cu}$ (tembaga) dalam tanah PSN mempengaruhi tingginya kadar logam $\mathrm{Cu}$ (tembaga) dalam sayuran yang tumbuh pada media tanah tersebut. Kadar logam $\mathrm{Cu}$ (tembaga) dalam tanah PSN sekitar 10 kali lipat lebih tinggi dibandingkan kadar logam $\mathrm{Cu}$ (tembaga) dalam tanah PSO. Hal ini menyebabkan kadar logam $\mathrm{Cu}$ (tembaga) dalam sampel sayuran PSN juga tinggi. Meskipun begitu, kadar logam $\mathrm{Cu}$ (tembaga) dalam tanah kedua lokasi PSN dan PSO masih di bawah ambang batas MAC in Agricultural Soil in China, yaitu 100 mg/Kg (Gambar 4).

Nilai faktor transfer (TF) logam berat dari tanah ke sayuran menurun menurut susunan $\mathrm{Cd}>\mathrm{Zn}>\mathrm{Cu}>\mathrm{Pb}>\mathrm{Hg}$ (Zheng et. al., 2007). Nilai TF ini berdasarkan ukuran jari - jari logam berat, semakin besar ukuran jari - jarinya maka nilai faktor transfernya akan semakin kecil. Selain itu, jenis tanaman yang ditanam juga mempengaruhi daya akumulasi logam berat dari dalam tanah ke bagian tumbuhan. 
Tabel 3. Penentuan Tingkat Cemaran Berbagai Sampel

\begin{tabular}{cccc}
\hline Sampel & $\begin{array}{c}\text { Kadar } \mathbf{C u} \pm \text { rata- } \\
\text { rata }(\mathbf{m g} / \mathbf{K g})\end{array}$ & $\mathbf{C} / \mathbf{P}$ & Tingkat Cemaran \\
\hline Sawi PSN & $6,270 \pm 0,0447$ & 1,254 & Sedikit Tercemar \\
Sawi PSO & $3,115 \pm 0,1270$ & 0,623 & Terkontaminasi Berat \\
Kangkung PSN & $17,525 \pm 0,0790$ & 3,505 & Cukup Tercemar \\
Kangkung PSO & $3,185 \pm 0,0675$ & 0,637 & Terkontaminasi Berat \\
Selada PSN & $6,965 \pm 0,0224$ & 1,393 & Sedikit Tercemar \\
Selada PSO & $2,875 \pm 0,0395$ & 0,575 & Terkontaminasi Berat \\
Tanah PSN & $40,530 \pm 0,3198$ & 0,4053 & Cukup Terkontaminasi \\
Tanah PSO & $4,380 \pm 0,1150$ & 0,0438 & Sangat Sedikit Terkontaminasi \\
\hline
\end{tabular}

Sumber: Data Primer (2015)

Tabel 3 dan Gambar 5 menunjukkan bahwa sayur sawi PSO, kangkung PSO dan selada PSO berdasarkan indeks C/P termasuk kategori terkontaminasi berat. Hal ini menunjukkan bahwa sayuran PSO merupakan bahan pangan layak konsumsi karena kadar logam $\mathrm{Cu}$ (tembaga) yang terkandung di dalamnya tidak memberikan dampak negatif pada kesehatan manusia yang mengkonsumsinya. Kadar logam $\mathrm{Cu}$ (tembaga) dalam sampel berbanding lurus dengan indeks $\mathrm{C} / \mathrm{P}$, yang artinya bahwa semakin tinggi kadar logam $\mathrm{Cu}$ dalam suatu sampel, maka akan semakin tinggi pula indeks $\mathrm{C} / \mathrm{P}$ sampel tersebut. Sebaliknya, semakin rendah kadar logam $\mathrm{Cu}$ dalam suatu sampel, maka indeks C/P nya akan semakin rendah.

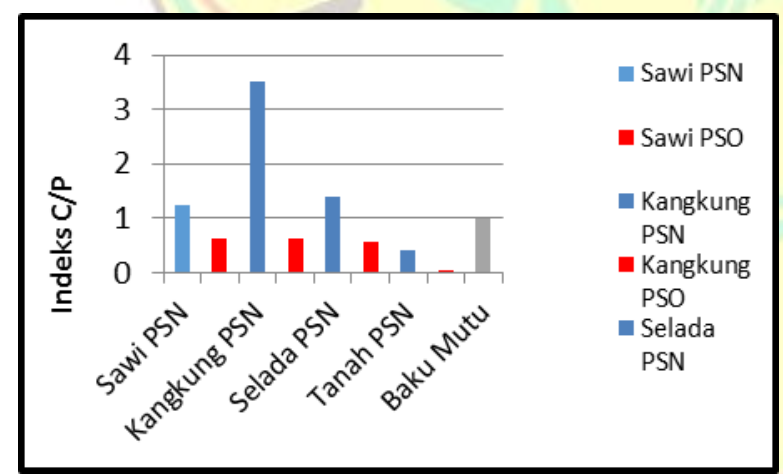

Gambar 5. Indeks C/P untuk Sampel Sayuran dan Tanah
Sampel sayuran PSN yang termasuk pada tingkat tercemar mengindikasikan bahwa sayuran mengandung logam $\mathrm{Cu}$ (tembaga) yang melebihi batas aman sehingga dikhawatirkan dapat memberikan dampak buruk bagi kesehatan manusia yang mengkonsumsinya secara terus menerus. Tingginya indeks $\mathrm{C} / \mathrm{P}$ dikarenakan tingginya kadar logam $\mathrm{Cu}$ (tembaga) dalam sampel. Tingginya kadar logam $\mathrm{Cu}$ (tembaga) dalam sampel PSN dikarenakan penggunaan pestisida yang mengandung sekitar $1-3 \% \mathrm{CuSO}_{4}$ (tembaga (II) sulfat), pupuk kandang, urea dan NPK secara berlebihan.

Sedangkan indeks C/P pada sampel sayuran PSO termasuk pada tingkat terkontaminasi yang mengindikasikan bahwa sayuran mengandung logam $\mathrm{Cu}$ (tembaga) namun masih dalam batas aman yang tidak memberikan dampak negatif terhadap kesehatan manusia yang mengkonsumsinya. Rendahnya indeks C/P pada sampel PSO dikarenakan rendahnya kadar logam $\mathrm{Cu}$ (tembaga) dalam sampel. Hal ini dikarenakan petani pada lokasi tersebut menggunakan pupuk cair yang terbuat dari hasil fermentasi limbah organik rumah tangga dan EM4 aktif 1\%. Petani setempat juga tidak menggunakan pestisida sintetik, mereka lebih memilih menggunakan pestisida alami.

Tabel 4. Data Hasil Penelitian 2 (Data Primer, 2015)

\begin{tabular}{ccccc}
\hline $\begin{array}{c}\text { Jenis } \\
\text { Pertanian }\end{array}$ & $\begin{array}{c}\text { Total Biaya Produksi } \\
(\text { Rp./ha/MT) }\end{array}$ & $\begin{array}{c}\text { Penerimaan } \\
(\text { Rp./ha/MT) }\end{array}$ & $\begin{array}{c}\text { Pendapatan } \\
(\mathbf{R p} . / \mathbf{h a} / \mathbf{M T})\end{array}$ & R/C \\
\hline PSN & 1.502 .200 & 10.348 .000 & 8.845 .800 & 6,889 \\
PSO & 378.800 & 2.915 .000 & 2.536 .200 & 5,795 \\
\hline Keterangan: & PSN & $=$ Pertanian Sayur Non-organik (Kebun Kartama) & \\
& PSO & $=$ Pertanian Sayur Organik (Kebun KOMPPOS - EM) & \\
& R/C & $=$ & &
\end{tabular}


Penggunaan pupuk kimia dan pestisida sintetik mengoptimalkan hasil panen sayuran di Kebun Kartama (PSN) hingga 90\% - 95\% dari jumlah benih yang ditanam petani, sehingga penerimaan (hasil penjualan) yang diperoleh petani juga maksimal yaitu sekitar Rp. 10.348.000,- /ha/MT. Sedangkan di Kebun KOMPPOS - EM yang tidak menggunakan pestisida sintetik dalam proses penanaman mengakibatkan hasil panen sayuran sekitar $80 \%$ dari jumlah benih yang ditanam petani. Hal ini dikarenakan banyaknya tumbuhan pengganggu di sekitar areal bedeng sayuran yang menyebabkan sayuran yang ditanam tidak maksimal pertumbuhannya, sehingga penerimaan yang diperoleh petani tidak cukup besar hanya sekitar Rp. 2.915.000,- /ha/MT.

Berdasarkan Pendapatan dan indeks R/C, diketahui bahwa usahatani sayuran, baik pertanian sayur organik maupun pertanian sayur non - organik, masing - masing merupakan usaha yang menguntungkan dan layak secara ekonomi. Namun, usahatani sayuran non organik memiliki pendapatan usahatani dan indeks $\mathrm{R} / \mathrm{C}$ yang lebih tinggi dibandingkan usahatani sayuran organik (Tabel 4). Hal ini menunjukkan bahwa usaha sayuran non organik lebih menguntungkan secara ekonomi bagi petani dibandingkan usaha sayuran organik.

\section{KESIMPULAN DAN SARAN}

Berdasarkan hasil penelitian yang telah dilakukan, dapat disimpulkan bahwa kadar logam $\mathrm{Cu}$ (tembaga) dalam sayuran dan tanah PSN sudah melewati baku mutu keputusan Dirjen POM RI yaitu 5,0 mg/Kg dan termasuk kategori tercemar logam $\mathrm{Cu}$ (tembaga). Sedangkan sampel sayuran Kebun KOMPPOS EM (PSO) masih berada dibawah baku mutu dan termasuk kategori terkontaminasi. Penggunaan pupuk dan pestisida sintetik yang melebihi dosis dan terus - menerus mempengaruhi kadar logam $\mathrm{Cu}$ (tembaga) dalam sampel sayuran dan tanah secara signifikan. Secara ekonomi, PSN dan PSO masing - masing merupakan usahatani yang layak diusahakan karena mampu memberi keuntungan bagi petani.
Rekomendasi untuk penelitian selanjutnya adalah perlu dilakukan penelitian lebih lanjut mengenai kadar logam $\mathrm{Cu}$ (tembaga) dalam berbagai pestisida dan pupuk yang digunakan petani sayuran dan pengujian kadar logam $\mathrm{Cu}$ (tembaga) dalam bahan pangan terutama sayuran di lokasi yang berbeda.

\section{DAFTAR PUSTAKA}

Charlena. 2004. Pencemaran Logam Berat Timbal $(\mathrm{Pb})$ dan Cadmium (Cd) pada Sayur - Sayuran. Program Pascasarjana S3 IPB, Bogor.

Darmono. 1995. Logam dalam Sistem Biologi Makhluk Hidup. UI-Press, Jakarta.

Husodo, S. Y. 2004. Pertanian Mandiri. Penebar Swadaya, Jakarta.

Panjaitan, Y. G. 2009. Akumulasi Logam Berat Tembaga $(\mathrm{Cu})$ dan Timbal $(\mathrm{Pb})$ pada Pohon Avecennia marina di Hutan Mangrove. Skripsi. USU, Medan.

Priyanto, B. dan Priyatno, J. 2007. Fitoremediasi sebagai Sebuah Teknologi Pemulihan Pencemaran, Khusus Logam Berat. Dikutip dari (http://ltl.bppt.tripod.com/sublab/lflora.ht m). Tanggal akses 29 Oktober 2015.

Putra, A. E. 2002. Analisis Limbah Industri Logam terhadap Kualitas Air Sungai Deli (Ditinjau dari Aspek Fisika dan Kimia). Tesis. USU, Medan.

Rumampuk, R. J. 2008. Efek Toksik Logam. Andi, Yogyakarta.

Setyawan. 2009. Sayuran Dataran Tinggi. Penebar Swadaya, Jakarta.

Simanjuntak, A. 2014. Status Lingkungan Pertanian Kota di Kecamatan Marpoyan Damai Kota Pekanbaru. Tesis. Program Pasca Sarjana Ilmu Lingkungan. UR, Pekanbaru.

Widaningrum, Miskiyah dan Suismono. 2007. Bahaya Kontaminasi Logam Berat dalam Sayuran dan Alternatif Pencegahan Cemarannya. Buletin Teknologi Pascapanen Pertanian, 3: 16 - 27 pp. 